\title{
SELF-EFFICACY AND THE PROCESS OF GAY SEXUAL IDENTITY DEVELOPMENT AMONG GAY MEN IN MALAYSIA
}

\author{
Carmella E. Ading ${ }^{1}$, Aminuddin Ibrahim Lastar ${ }^{1}$, Getrude Cosmas Ahgang ${ }^{1}$, \\ \& Mohammad Hashim Othman ${ }^{2}$ \\ ${ }^{I}$ Faculty of Psychology and Education, Universiti Malaysia Sabah (Malaysia) \\ ${ }^{2}$ School of Educational Studies, Universiti Sains Malaysia (Malaysia)
}

\begin{abstract}
The development of gay identity sexual among Malaysian gay men were not discussed openly in this country. This is because the government do not approve same sex orientation lifestyle. However, gay men exist in many communities in this country and they are living freely as a citizen and work in the country like others. Malaysia is one of the countries that openly against the Lesbian, Gay, Bisexual, Transsexual and Queer (LGBTQ). Nevertheless, they continue to develop their sexual identity as a part of their lives which at the same time causes a great distress in them. Thus, their decision to identify themselves as gays takes huge courage and effort. These courage and effort were found not only just intricately, since it involves emotional and social support from their family, friends and communities. It is also believed that this social support might help gay men to develop their self-efficacy as well. Therefore, it is in the interest of the researchers to explore about self-efficacy by looking at emotional and social support they received and its relation to the development of sexual identity among the gay men who lives in Malaysia. In this qualitative research, semi structured questions were developed to explore sexual identity development among the gay men. Six (6) respondents who have identified themselves as gay, aged between 21- 44 years old, from different walk of life were interviewed. Data were analysed using thematic analysis. Our study has found that emotional and social support, are the important factors that contribute to their self-efficacy and help them in developing their sexual identity.
\end{abstract}

Keywords: Sexual identity, gay, self-efficacy, Malaysia.

\section{Introduction}

Malaysia is one of the countries that consider homosexuality is a criminal offense. Individuals who are committed to homosexual practices will be penalized under the Malaysian Civil law or the Shariah law. See (2019) stated that Malaysia's understanding of sexuality and gender fails her international standards and best practices. Survey conducted by PEW research centre in 2013 has also shown that $86 \%$ of Malaysian believe homosexuality should not be accepted by the society. Due to these facts, individuals who realised that they have same sex attraction may find themselves experiencing cognitive dissonance. This is because they are living in the society that openly against homosexual practice. In addition, Kuga Thas (2013) states that adult homosexuals and adolescent homosexuals in Malaysia have a tendency to experience depression and suicide as a result of social pressures. Dworkin \& Yi (2003) stressed that gay men were more likely experiencing discrimination and assault by the homophobic individuals. This gives the impression that negative experiences, oppression and pressure from a society that rejects homosexuals contribute to extreme stress and suicidal tendencies among homosexuals.

It is important that public should understand them and to understand them it is crucial for everybody to know the process of gay sexual orientation and identity development (Bailey, et al., 2016). The development of gay sexual identity among LGBTQ has consumed not just their emotions as it is an unprepared process but also found as unsupported, inconsistence, incongruence and stigmatised (Rosario, et al., 2006) in the society which do not eccept or understand LGBTQ. This may hinder the discomfort feelings by having friends or not wanting to have friends among the LGBTQ as reported in Mohr $\&$ Sedlacek (2010) due to the barrier of lack of commonalities.

\subsection{Gay sexual identity and social support}

Sexual identity refers to how individuals conceptualize their romantic or sexual attractions to other persons (Tatum, 2018). It was largely found that some LGBTQ individuals choose not to disclose their sexual orientation identity, a concept known as "passing" (Hoffshire, 2017). The concept of passing 
represents the notion that homosexuality is an invisible identity which often can be hidden from others. Berger (1992) also commented that passing leads to poor self-concept and potential emotional distress. Since gay men were more satisfied with social support available from those who knew their sexual orientation, Berger (1992), has also stated that most gay men were known as gay only to most members of their networks. Besides that, close friends, siblings and persons who are close to them were also more likely to be aware of their homosexuality than co-workers, parents, and more distant relatives. Therefore, in most matters regarding personal issues these individuals choose to seek help or discuss their problems with their closed ones who are in return will not weaken them as LGBTQ but who could understand them better. These close friends are usually from the opposite gender as Gillespie et al. (2015) found that LGBTQ individuals have fewer same-gender friends in comparison to heterosexual individuals.

The development of gay sexual identity is also believed to be well support by close friends who understand and accept LGBTQ. Another encouraging finding by Mohr and Sedlacek (2010) that involved 2,925 college freshmen at a State University revealed that $42 \%$ of the students reported having or wanting to have LGBTQ friends is an indication of support these individuals have. In a study conducted Gillespie et al. (2015) found that, expressive, instrumental and companionate types of friendships are important and strongly associated with LGBTQ overall life satisfaction which derived from the process of adopting the identity consistently (Rosario, et al., 2006) and eliminating the undesirable dissonance between their demeanours and distinctiveness as LGBTQ.

\subsection{Self-efficacy and reassurance}

As it is well defined by Bandura (1994, 2006a, 2006b) and Gecas (1989) self-efficacy is individual's sense of self-agency, borne out in a belief that they can accomplish a given task and, more broadly, cope with life's challenges. Besides, Bandura $(1986,1997)$ has also stated that the possible consequences of behaviour which being predicted are intensely affected by self-efficacy as well.

In order to understand gay sexual identity development, it is important as well to understand the concept of high self-efficacy and low self-efficacy. As suggested by Karbasi \& Samani (2016) individuals with high self-efficacy tend to engaging in make it happens compared to individuals with low self-efficacy who prefer to avoid from engaging in it all together or just by let it be as it is. In conjunction with developing gay sexual identity, higher self-efficacy leads individuals to enthral themselves in the process of integration, incorporation and consolidation of LGBTQ self (Rosario, et al., 2006). These processes which involve milestones and courage are necessary in high self-efficacy otherwise the reassurance elements desired will be neglected hence leaving these individuals struggling in finding their true sexual identity.

Though, in other study findings gay and lesbian students' level of self-esteem and self-efficacy were high (Jurial, Otig, and Gallinero (2015) which suggest that they have a positive attitude about themselves, and they believe they can surpass almost all the challenges that come in their way. The study also revealed that students' level of self-efficacy showed a strong positive relationship with affective and cognitive engagement. It can be assumed that that their positive beliefs that they can surpass their problems can be strongly associated with how much they engage affectively and cognitively. As suggested in the earlier study of Rosario, et al. (2006), youth gays and lesbians may have gone through the whole process of LGBTQ milestones, before they could reliably accommodate themselves as one.

\section{Objective}

The objective outline of this research was to explore how emotional and social support from friends and family could contribute to gay men's self-efficacy in developing their gay sexual identity. This is based on the notion that, gays who are living in a country which is not supporting LGBTQ are facing with great distress in identifying themselves openly. They may be seen as different from the majority and it takes such a huge courage and effort resulted from their high level of self-efficacy to be able to stand up as gay. These internalised strong will of emotions coupled with social supports from close friends and family have probably helped them in the development of their self-efficacy that needed to be explored in order to understand them better.

\section{Methodology}

A Grounded theory approach were used in this research. The Grounded theoretical approach helps researchers to explore and understand the process of gay sexual identity development and its relation to self-efficacy. Participants in this study were recruited via snow balling technique as the research target group were gay men. Six respondents were interviewed in this study. The sample size of the study was sufficient enough for the saturation condition because after interviewing all the six respondents, there were no new data found or relevant to the study. This is in line with the statements of Strauss and Corbin (1998) 
stated that when saturation can be achieved while no new or relevant data appears. Therefore, categories are constructed according to the characteristics and dimensions that indicate variation, and the relationship between themes in the data is robust and valid (Strauss \& Corbin, 1998). In supporting the stand, Romney, Batchelder and Weller (1986) have also stated that a sample as small as four individuals can provide perfectly accurate information with a high level of confidence (.999) if they have a high level of competence in the field studied.

In this study, the researchers used a semi-structured interview. There were 2 sections in the interview session, namely Part A and Part B. Part A involves demographic data such as age, level of education, occupation, race, place of residence, country of origin and if the respondent is in intimate relationship with a spouse. While in section $\mathrm{B}$, the questions are focusing on the exploring of the emotional and social support they received and how it contributes to their self-efficacy and process of gay identity sexual development. In light of constructing semi-structured interview protocol items that meet the purpose of the study, researchers used questions constructed by Degges-White and Myer (2005) based on Cass (1979) model as the guideline. A pilot study to formulate the questions constructed for the purpose of data collection that answered the research questions was then administered.

As for the validation process, the interview questions were reviewed by two experts in the field of counselling and psychology. These two experts were selected based on their experiences in the study of homosexuality. It is important to highlight that the items formulated in this semi-structured interview are serve as guideline which the researcher may expand further exploration in necessity in order to obtain the information needed as outlined in the study objectives. All interviews conducted were recorded with the consent from all respondents and it was used for the purpose of data transcript. The duration of the interview was about two hours.

\section{Analysis}

Sexual identity is a process. It involves different types of attractions to others, as in this case on the same-sex persons. These attractions can be divided into two types of urges that is sexual intimacy or the urge to develop intimate relationship with another male. In this study, it was found that four of the participants were aware of their initial aspiration to same sex attraction when they were in early teenager and one of the participants was aware that his same sex attraction started to emerge while he was 7 year old.

The analysis from the interview revealed that three participants were found to accommodating their same sex attraction from the beginning and started to develop their gay identity secretly while the other three participants did not accept their same sex attraction in them and denied the desirability towards same sex at the early stage because they wanted to be accepted by the society and do not want to bring shame to their family. However, those three began to accept their same sex attraction desire after experiencing a turning point in their lives that made them started to think about their true sexual orientation.

\subsection{Self-denial through suppressing and rejecting same sex attraction feeling}

Three participants underwent a denial process in which they did not accept same-sex attraction because they knew same-sex relationships were prohibited and will somehow affected their families in many ways. As the result, they chose to suppress their feeling towards same-sex aspirations that they had.

Participant 1 suppressed his feelings after his father asked him off his same sex attraction inclination and warned him not to hold on to that idea by any change. That incident has made participant 1 to suppress his feeling and did not want to think about it. This took place as at the time of happening he wished to comply with the society's rules and his family's expectation. While the findings in Participant 2 who had also underwent same-sex attraction suppressed revealed that he never talked about same-sex attractions or anything in line with the matter to other individuals because as a young adolescent he wanted to be accepted by the majority group as one of their male members.

It was found clearly that both participants had experience suppressed emotion and did not think about their same sex attraction because they knew that same sex attraction is not acceptable in the society and could affect them and their family in return as in shown in their verbatim excerpts below.

\section{Participant 1: $\quad$ "when I, was approached by my dad. He asked me if I am, and me trying to conform with society and even their expectation as parents, I must suppress and I don't want to think about it, and I start dating..." (B49)}

Participant 2: 'I suppressed. You don't talk about it, you don't discuss about it, you don't mention to people. And then you, when you were young, you're want of fit in, when you're young you just want to be like everyone else" (B74)

Besides self-denial by suppressing emotions towards same-sex attraction and fantasy, this study has also able to disclose the act of emotional rejection towards same-sex feelings predisposition among the 
participants. It was found that one of the participants resorted to reject his feelings of same-sex attraction. This is because according to him, he knew it was wrong to have same sex fascination and therefore has tried to get a girlfriend in order to prove to him and society that he is a heterosexual. The verbatim excerpts below shows his intention and example of his self-rejection act towards same-sex feelings.

Participant 3: "So in between that 12 years old until 14 years old I tried to find girlfriend, because to help me not to become gay. I want to have a girlfriend so that I can have feeling towards girls like that. It's my own way lah, I have to find girlfriend..., if not I become gay" (B43)

The above verbatim excerpts from the interviews showed that society rules, friends and family were the pushing factors that lead to decision making in self-denying and self-rejecting on same sex attraction.

\subsection{Emotional and social support}

Having accepted their own sexual identity, it was found that participants started to look for emotional and social support. They will turn to their good friends or individuals that can accept their sexual identity. However, at their earlier stage of self-acceptance, they were only feeling comfortable and willing to disclose their same-sex attraction feelings to certain individuals because they were still unsure and fear of rejection from the society. The verbatim excerpts below describe how important emotional and social support are to them in their lives.
Participant 1:
"I do, I do. But normally we mixed with my only group. That's why, that's why once you out ah, you got to have a support group”. (B924)
Participant 2:
"I grew and then I got involved with my first boyfriend. We were very happy. I was happy, so happy. I was so happy because I could be myself. But, because there was so new, so fresh, I was closeted.” (B218)
Participant 3:
"I more prone to hang out with the people that accepted me”. (B503) the club, but I feel I can share anything with them because they are gay like me" (B302)
Participant 4: "I never thought this community (gay) existed. Though I do not know anyone in

It is shown that through this process, social support has a positive impact on each participant and this gives them the motivation to remain positive in continuing life as gay. Participants also prefer to associate with individuals who can accept their sexual identity. This is because they do not want to feel marginalized by the society. The majority of the participants prefer to associate with gays because they feel there is unconditional acceptance. This is also having proven that emotional and social support were playing important role in the contribution of self-efficacy among gays.

\section{Discussion and conclusion}

In this study, it was found that emotional and social support from friends or individuals that accepting participants' same-sex attractions contribute to their development of self-efficacy. As most of the participants for this study indicated that without social supports from those who are close to them it is very difficult for them to accept themselves as gay. Their self-acceptance as gay man definitely did not come that easy for them. They were struggling with their emotions and in battle between trying to understand who they are and social acceptance.

Half of the participants admitted that they were once in self-denial and self-rejection due to pressure that they received from family and society in a way or another. From this study, it is also made known that stigmatization and complying with society norms are the two most important elements which have pushed same-sex attraction men to suppress their true inner feelings towards their sexual disposition. The elements of denial and rejection are so huge which disable them to be truthful to themselves. It was clearly stated by one of the participants who was trying at his best to get a girlfriend just to prove to himself and society that he is not interested in same-sex.

In the process of understanding one's self, same-sex attraction men need high self-efficacy for them to be able to feel comfortable and to trust others as stated by one of the participants who has said that he can talk about anything with other same-sex attraction men because they are just like him who are sharing the same attraction towards same-sex. While another participant mentioned that he is comfortable to socialise with his group members because he knows there is where he could get all the emotional and social supports from. As confirmed by another participant in this study that being with the same-sex attraction men would make him happy because he can be in his true self. In supporting this, previous research done by Jang, Smith and Duys' (2019) revealed that LGB who obtain positive social support may experience understanding towards oneself, especially when perceiving painful experiences as a common part of the human experience. 


\section{References}

Bailey, J. M., Vasey, P. L., Diamond, L. M., Breedlove, S. M., Vilain, E., \& Epprecht, M. (2016). Sexual orientation, controversy, and science. Psychological Science in the Public Interest, 17(2), 45-101.

Bandura A. (1986). Social foundations of thought and action: a social cognitive theory. Englewood cliffs, NJ: Prentice Hall

Bandura, A. (1994). Self-efficacy. In V.S. Ramachaudran (Ed.), Encyclopedia of human behavior (vol. 4, pp. 71-81). New York, NY: Academic Press

Bandura, A. (1997). Self-efficacy: the exercise of control. New York, NY: Freeman.

Bandura, A. (2006a). Guide for constructing self-efficacy scales. In F. Pajares \& T. C. Urdan (Eds.), Self-efficacy beliefs of adolescents (pp. 307-337). Greenwich, CT: Information Age Publishing.

Bandura, A. (2006b). Toward a psychology of human agency. Perspectives on Psychological Science, 1(2), $164-180$.

Berger, R. M. (1992) Passing and Social Support Among Gay Men, Journal of Homosexuality, 23(3), 85-98, doi:10.1300/J082v23n03 06

Cass, V. C. (1979). Homosexual identity formation: A theoretical model. Journal of Homosexuality, 4(3), 219-235. doi: 10.1300/J082v04n03_01.

Degges-White, S. E., \& Myers, J. E. (2005). The adolescent lesbian identity formation model: Implications for counseling. The Journal of Humanistic Counseling, Education and Development, 44(2), 185-197.

Dworkin, S. H \& Yi, H. (2003). Lgbt identity, violence, and social justice: The psychological is political. International Journal for the Advancement of Counseling, 25(4), 269-279.

Gecas, V. (1989). The social psychology of self-efficacy. Annual Review of Sociology, 15, 291-316.

Gillespie, B.J., Frederick, D.,Harari, L., \& Grov, C.(2015).Homophily, close friendship, and life satisfaction among gay, Lesbian, heterosexual, and bisexual men and women, PLoS One.doi: 10.1371/journal.pone.0128900

Hoffshire, Michael D., "Examining the Impact of Sexual Orientation on the Career Development of LGBQ+ Students" (2017). University of New Orleans Theses and Dissertations. 2328. https://scholarworks.uno.edu/td/2328

Jang, H., Smith. C.K., \& Duys, D. K. (2019). LGB identity and career decision-making self-efficacy among sexual minority college students,International Journal for Educational and Vocational Guidance https://doi.org/10.1007/s10775-020-09428-1 13

Jurial, M.G., Otig, V. \& Gallinero,W.(2015).The Relationship of Self-Esteem and Self-Efficacy to Student Engagement among Gay and Lesbian Students: A Case Study, Journal of Higher Education Research,11(1)

Karbasi, S. \& Samani, S. (2016). Psychometric properties of teacher self-efficacy scale. Procedia - Social and Behavioral Sciences, 217, 618-621.

Kuga Thas, A. M. (2013). No right to live? Malaysia's Islam and implications for its sexual minority storytellers. In. G.J. Fairbairn, \& R. Fisher, (Eds.). Proceedings of the 4th Global Conference: Storytelling, (ms. 1-21). Diperoleh daripada http://eprints.qut.edu.au/64539/

Mohr, J.J., \& Sedlacek, W. E. (2010). Perceived Barriers to Friendship with Lesbians and Gay Men Among University Students, Journal of College Student Development, 41(1),70-80

Pew Research Center. (2013). The Global Divide on Homosexuality: Greater Acceptance in More Secular and Affluent Countries. Retrieved from http://www.pewresearch.org/wpcontent/uploads/ sites/2/2014/05 /Pew-GlobalAttitudes-Homosexuality-Report-REVISED-MAY-27- 2014.pdf

Romney, A., Batchelder, W., \& Weller, S. (1986). Culture as consensus: A theory of Culture and informant accuracy. American Anthropologist, 88, 313-338.

Rosario, M., Schrimshaw, E. W., Hunter, J., \& Braun, L. (2006). Sexual identity development among gay, lesbian, and bisexual youths: consistency and change over time. Journal of sex research, 43(1), 46-58. https://doi.org/10.1080/00224490609552298

Strauss, A., \& Corbin, J. (1998). Grounded theory methodology. Handbook of qualitative research. 273-285.

See, J. (2019). Challenges to Mental Health Access among LGBT People. Policy for Action 2/2019.

Tatum, A. (2018). "Workplace Climate and Job Satisfaction: A Test of Social Cognitive Career Theory (SCCT)'s Workplace Self-Management Model with Sexual Minority Employees". Dissertations. 2984. https://ecommons.luc.edu/luc_diss/2984 